\title{
A Survey on Routing Protocols for the Underwater Wireless Sensor Network
}

\author{
Reeta Bhardwaj \\ Assistant Professor (IT) \\ Daviet, Jalandhar
}

\author{
Harpreet Kaur \\ M-Tech (CSE) \\ Daviet, Jalandhar
}

\author{
Rajeev Kumar, PhD \\ Assistant Professor (IT) \\ Daviet, Jalandhar
}

\begin{abstract}
Underwater wireless sensor networks (UWSNs) obtained the information from the underwater sensors nodes. In which there are lots of issues and difficulties in underwater like size, limited battery power, deployment and limited bandwidth capacity. In underwater, it is difficult to recharge or substitute the battery of the sensors nodes. In such circumstances the concentrate on reducing the battery utilization of the sensors nodes. There are various techniques are used to reduce the battery utilization. The design of routing protocols for underwater sensor networks creates numerous challenges due to essential properties of the underwater environment. Many routing protocols have been proposed in order to provide an efficient, reliable and route discovery between the sources and the sink. It also has more through-put as compared to the existing technique. In this paper, display a survey and comparison of various groups according to their taxonomy with their ability is discussed in detailed.
\end{abstract}

\section{Keywords}

Types of UWSN, application, the architecture of UWSN, the taxonomy of routing protocols

\section{INTRODUCTION}

Wireless sensor networks (WSNs) perform on land [1]. It requires air as communication channels for transmission. It needs electromagnetic waves for transfer the information (data or voices). Whereas underwater sensor networks (UWSNs) are performed on the water. In which water is essential as communication channels for intercommunicating. It chooses the electromagnetic radio waves, optical waves and acoustic waves for communication. UWSN uses some properties of terrestrial sensor network likewise a large number of nodes and power issues. Firstly radio waves spread at deep partition through conductive sea water at small frequencies that are 30 to 300 hertz. It needs an incredible reception equipment and high power utilization for communication. Hence it is not suitable for UWSNs. Secondly, optical waves do not suffer from very high attenuation. Furthermore, optical waves don't experience the ill effects of high reduction. Moreover, it needs high accuracy narrower laser beam for carrying the information. Hence optical waves are ideal for short range communication in an underwater. Thirdly Due to the downsides of radio waves and optical waves. Therefore acoustic waves are utilized for communication in UWSNs. It is expected that sensor nodes are static in WSNs with these diverse topologies can be connected. However, static nodes are constant for communication joins. In the underwater continuous development of the nodes $1-3 \mathrm{~m} / \mathrm{s}$ with water streams, so the system can't be seen as a settled topology. Route optimization is not more challenging in moving nodes but in the link, stability is an important issue. There are a few plan challenges in UWSNs [3]. Size and cost: The underwater sensors nodes are costly gadgets because of handset equipment require shielding from the extraordinary underwater condition and thus these are very expensive.
Whereas terrestrial sensors nodes are smaller in size and they are inexpensive. Deployment: The deployment is sparser in underwater due to cost and challenges involved. While in terrestrial sensor networks are densely deployed. Power: The acoustic underwater communication needs high power as compare to terrestrial communication. In which it has greater distance and more power complex signal processing needed at the receiver. In the underwater higher capacity of the battery is required. In which more energy consumption is needed. Memory: Wireless sensor nodes have less capacity limit. Underwater sensor nodes require more information transferable because of discontinuous channel requirement. There are various types of sensors networks as following: [2]

Terrestrial WSN: Numerous nodes which are low cost are gathered on an area in an ad hoc manner. The terrestrial sensor nodes are mainly equipped with secondary power sources. The sensor nodes can easily communicate with the base stations and send the data back to them.

Underground WSN: The location of these types of networks is mainly in areas which are underground or in caves etc. they are used to monitor the underground conditions only. There is also a need of providing some extra sink nodes on the ground. These are used to send the information from the underground networks to the base stations.

Underwater WSN: The sensor nodes are placed underground in these types of networks. Underground vehicles are used to gather the information from these networks. The placement and maintenance of these types of networks are expensive. So there is a use of very less number of networks.

Multi-media WSN: The reporting of the certain area is the basic idea behind these types of groups of networks. The sensor devices involved in these types of networks are able to store, retrieve and process the data which is produced in the form of videos, images, and audios. Mobile WSN: The mobile sensor networks which can travel from one place to another and can also communicate with the external environment are involved in these types of networks. The sensing, computing and communicating properties are thoughtful of these types of nodes.

UWSN applications in light of acoustic communication are quickly picking up occurrence for make powerful progress in the range of sea checking and observatory frameworks, remote ocean investigation and taking after of various substances of the sea-going condition and uncovering resources. Underwater acoustic sensor nodes (UASNs) find their applications in fields like seaward oil and gas reflection, oil drops, military watchfulness and perception, field acknowledgment, contamination controlling, common disasters like a wave and brutal windstorm expectation, coral reef and natural surroundings controlling of amphibian life and fish munching to give some examples.[4] 
a. A deepwater acoustic system for extract countermeasures functions: This procedure permits the sending of an underwater acoustic system for communication and permits the AUVs to layout range using its sonar and a while later characterizes potential targets. The system concedes for the association between numerous AUVs and they can exchange the information to each other for a viable agreeable counter the degree operation. The acoustic modems used for communication are WHOI Smaller scale models working at around $25 \mathrm{kHz}$ and a bit rate of $80 \mathrm{bps}$ with the transducers mounted on the body of the AUVs for most extreme scope [4].

b. Remote sensor arranges on the enormous hindrance reef: Here, the sending of underwater sensor organize equipment is done to concentrate the impacts of temperature, light force, saltiness and other climatic conditions on coral dying. All through the examination, the group stressed on using time tried, however, costly conventional underwater sensors rather than untested and modest sensors, for instance, a solitary sensor crumple can realize an immense misfortune regarding vessel and workforce time.

c. UASN for early cautioning era of characteristic occasions: This innovation speaks to the physical layer challenges in outline and improvement of a dependable, profound physical capacity in UWSN that can be generally utilized for early notices against normal catastrophes like surges, tidal waves, seismic tremors, and sea tempests. Markers, for instance, seismic development, changes in water aggravation, temperature and modification in the environmental recurrence can be measured by utilizing underwater sensor systems giving intensive data on any moving toward catastrophe as in front of the calendar as a couple days.

d. Sensor organizes structures for checking underwater pipelines: An acoustic correspondence model is used to measure aggravations in light of vibrations in landed pipeline underneath $1 \mathrm{KM}$ on an uneven and rough ocean bottom where most parts of the pipeline aren't touching the seabed, from now on significantly helpless to extreme vibrations in the midst of strong streams.

e. Self-governing underwater observation sensor arranges (ASSN): Here, a sub-ocean remote system is to be conveyed in remote ocean unfriendly domain of working significance. ASSN can gather, process, store and forward basic observation information using acoustic modems to land, air, space or a neighboring center/ship to repair sharpness and status to any surprising conditions. The data is collected at frequencies as low as $500 \mathrm{~Hz}$ and still not as quite a bit of applying acoustic line clusters that are arranged at the bottom of the ocean in the territory of the process. Beforehand the data is accomplished it is prepared for each dependent strategies and record on persevering accumulation reachable in the location of that specific range. A short time later, the data is sent to a permission center point that is introduced on the seabed by methods for underwater acoustic modems. The induction center point has hopeful passage that it will release to the surface of the sea over and over after foreordained interims or when there is adequate data and it transfers the investigation data to the neighboring base station sub-structure for observing and control [4].

\section{THE UNDERWATER WIRELESS SENSOR NETWORKS}

Mobile number of sensors nodes exist in the UWSNs [34] and uncontrolled underwater vehicles redistribute in underwater. In the underwater places of the sensor, nodes are utilized to execute helpful controlling work and examination or amassing data from the sensor nodes are utilized as a part of reallocating underwater vehicles. Different applications can be utilized as a part of UWSNs like helped route, oceanographic information gathering, and the location of contamination level, seaward movement examination, debacle avoidance, and strategic perception and anticipate regular unsettling influences in the sea. The capacity of these systems to control hunt and way underwater advancement has expanded the consideration of building the UWSN. Underwater sensor nodes and underwater vehicles must have self-plan potential. Underwater sensor nodes might be migrated because of development by the fluid procedures like the shift in weather conditions and scattering. Keeping in mind the end goal to support correspondence after expulsion by streams and dissemination, the sensor nodes ought to have the proficiency to rework the system. Sensor nodes ought to have broad information of system while, taking part parameter subsequent to joining automatic design.

They should have the capacity to synchronize their operation by trading different parameters with respect to arrangement, area, and development operation and to transmit checked information to some on-shore station.

There are three different structures as uncovered in figure 1 for UWSNs: Sensor nodes are attached to the bottom of the sea with nonstop sea reside. By methods for remote acoustic connections, underwater sensor nodes are interconnected to at least one underwater sinks (UW-sinks). UW-sinks are furnished with two acoustic handsets, flat and vertical handset [34].

The shell station is fit for with various acoustic handsets, one for each UW-sink sent. It is likewise proficient with an expanded assortment of RF or satellite transmitter to speak with the coastal sink (OS-sink) or to a surface sink (s-sink). Sensor nodes float at differing depth with a specific end goal to check a specific trial. The possible clarification to accomplish diverse depth is joined each UW-sensor node to a surface float, by methods for wires. They may likewise essentially recognize and deactivate with the enemy in the military setting.

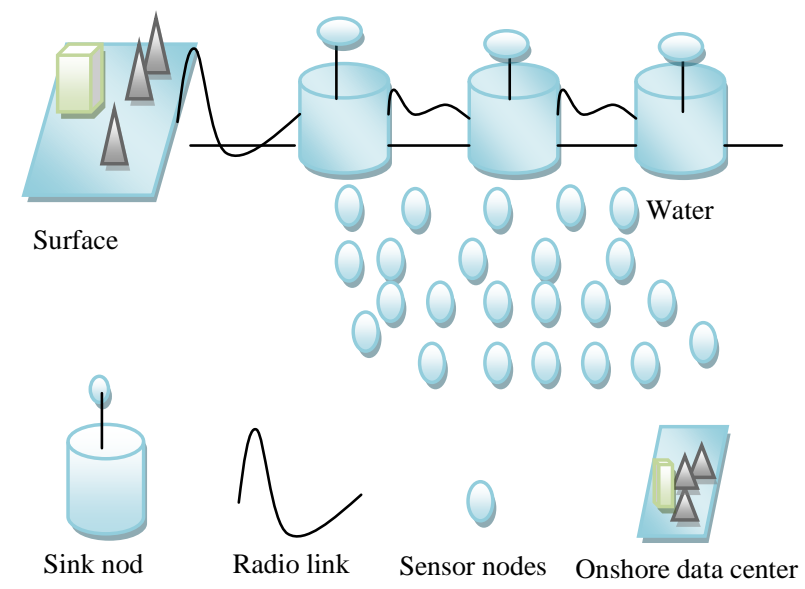

Figure 1: Architecture of UWSNs [34]

Static Two-Dimensional Underwater Sensor Systems: For sea base observing [37] every node attached to the sea base. An underwater sink aggregates the data from the sensor nodes by the even recipient. At that point, it transmits the data to a surface station by the vertical handset. Just before transmit with the on solid land and the surface station sinks have RF flag. Utilizing direct associations or multi-jump tracks the sensors transmitted with the sink. In the immediate association, every 
sensor specifically transmits data to the chose sink. This may not be the biggest vitality effective. In multi-bounce track, the source sensor conveys the information to the focal sensors until touch base at the sink. This secures the vitality and augmentations the system scope.

Static Three-Dimensional Underwater Sensor Systems: For sea section checking. All nodes shut to support by a wire. The sense information transmits to the center station by the float utilizing RF flag. Be that as it may, skimming floats may piece ships exploring, or can be seen and killed by adversaries in military applications.

Three-Dimensional with Self-ruling Underwater Vehicles: For underwater investigation. It comprises of bunches of static sensors together with some independent underwater vehicles (AUVs) AUVs assume a key part for extra support in information reaping. AUVs measured as super nodes, which have extra vitality, can move independently and it may be a switch between settled sensors, or an administrator for system reconfiguration, or still, a typical sensor [38] propose a specific engineering for UWSNs to supply vitality effective and solid basic plan.

Whatever is left of the paper is sorted out as take after. Taxonomy of UWSNs routing protocols discussed in section III. In section IV related work is discussed. Segment V we show the execution correlation of UWSNs routing protocols. The conclusion is determined in area VI and references are indicated at the last some portion of the paper.

\section{3. TAXONOMY OF UWSNS ROUTING PROTOCOLS}

The most generally utilized procedures keeping in mind the end goal to break down the execution of earthly and underwater acoustic sensor systems are diagnostic demonstrating, the unique course of action, and numerical reform. Each method has its own advantages and disadvantages depending upon on the considered system attributes. Right off the bat, logical demonstrating techniques are extremely difficult in the underwater plan. Because of its hugeness flexibility and rigidity when compare with conventional sea observing methodologies in UWSNs are straight up clearly increasingly vital in underwater information communication for the years to come. As all discussion in the bottom segments, it demonstrates that UWSNs have increased much focus with enough outcomes proposed. In any case, many difficulties to all the UWSN analysts, unrefined underwater condition, equipment restrictions and complex application plan still work. In view of the writing studied below, the associated potential behavior may value the consideration of the present and future scientists inspired by UWSN.

In figure 4 the taxonomy of UWSN protocols conventions as indicated by their capacity in which it isolates into three segments as location-based routing, cluster based routing, and hierarchical based routing. Location based routing sensor nodes are addressed by means of their locations and it is discussed by various authors and each one can give a better result as compared with another routing protocol. In table 1 depict the correlation of routing protocols based on their characteristics which are discussed in figure 4 based on their proficiency. Clustering: The networks have a lot of sensor nodes attached within one single area. The battery powering is applied to all these networks for the availability of the networks at all times. The networks which are placed in an unprotected environment are not very proper in the case of security. The privacy is deployed in these types of networks due to these reasons. Also, it is not possible to charge the batteries of so many nodes in the networks. So, various techniques have been developing to provide the energy consumption of nodes in an easy manner. The clustering technique has proved to be a much efficient method in saving energy. Clusters are selected amongst all the other networks due to the following factors [35]:

Clustering of nodes demonstrates that system is more steady and effective.

Clustering of nodes is situated in any event separate and higher energy by important position.

Clustering decreases activity system and increment execution.

The selection of the cluster head is a very important factor. Also, the various protocols are required for this method. The involvement of protocols and their selection are very important factors. All these affect the network system collectively in various manners. Cluster development: An elite and an extremely basic calculation that is the $\mathrm{K}$ implies calculation is utilized to take care of the vast majority of the clustering issue. Cluster head: Once the formation of clusters is done, recomputation of the centered of clusters is performed. The centered point of each cluster in the network is calculated. Now, the new coordinate which is considered for further calculations is the centered point. This coordinate is not equal to any of the earlier positions of the sensor nodes. As it is a location based clustering scheme, the selection of this coordinate as a cluster head is not possible. The minimum distance between the cluster members as well as the centered position is to be calculated once the position of the centered is known as shown in the figure. Sometimes it is possible that the threshold value decreases then the fixed threshold value decided. Due to this the cluster head also reduces. So to solve this problem in this kind of situation, recalculation of the cluster head is done which is based on the minimum distance and the highest energy recorded [36].

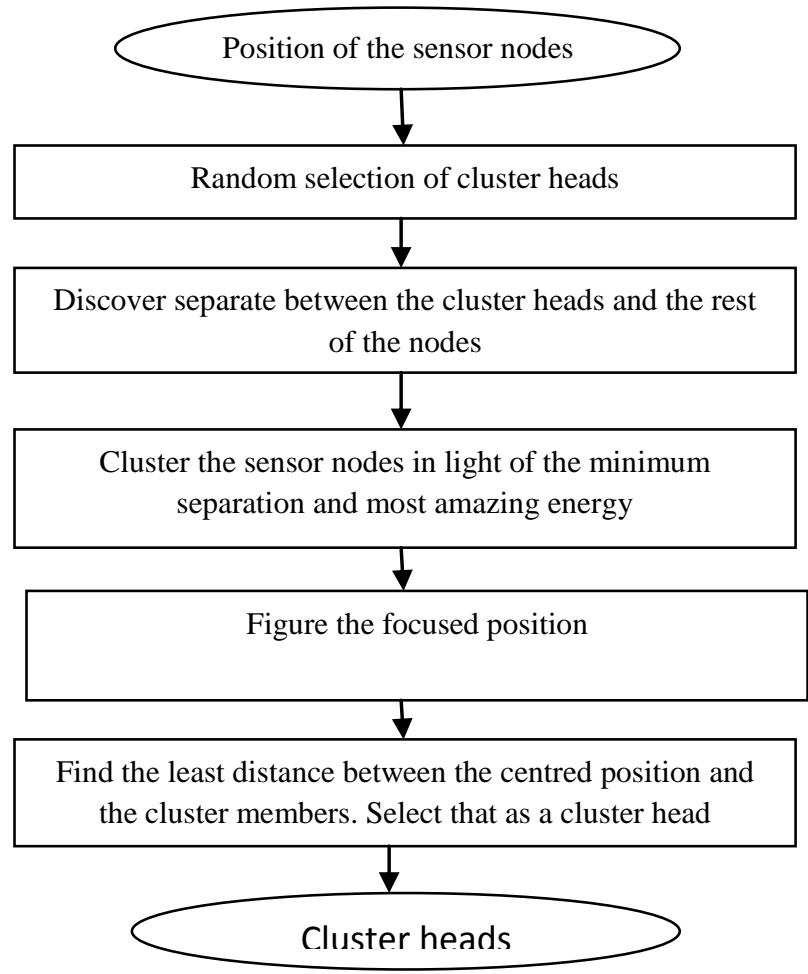

Figure 2: System Architecture for the Clustering of Nodes [36]

Location of sensor node: For the formation of a cluster in the 
UWSNs, it is required for every sensor node to know its area data. The area data of the nodes which are conveyed is known. To calculate the estimated distance between two sensor nodes, coordinates $(x i, y i)$ [36] are used. A clustering algorithm is used for the clustering of the sensor nodes on the basis of the minimum distance and highest residual energy. Any of the localizations methods can be used by the node after the gathering of information regarding the angles, distance and the positions of it. For the computation of the position of the nodes, various methods are used such as multi-alteration, etc.

Hierarchical based routing cover the essential architecture of the hierarchical routing protocols with data forwarding mechanism, route discovery, and maintenance. In which, there is various routing protocols that have been discussed below as Multi-Path routing, Minimum Cost Clustering Protocol (MCCP), temporary cluster based routing (TCBR), Hydro-cast routing protocol. In which every protocol has some issues, likewise in the multi-path vertical sink. Multipath data transmission mechanism is not suitable for the underwater environment. If the path terminates then the overall network throughput will be affected and it also affected on packets delivery when void regions occur. Another routing protocol that is [25] temporary cluster based routing is an energy efficient routing protocol in which the cost of TCBR protocol increases with the usage of the extra mechanical module in the courier node. In the hydrocast routing protocol [15] multiple copies of the same packets have been received by the sink node which will enhance the extra load on the network. Where the energy efficiency is hidden. However, the application that requires for scalability to hundreds or thousands of nodes it mainly helpful for hierarchical clustering. To prolong the battery lifespan dynamic clustering offers flexibility.

Underwater Wireless Sensor Network

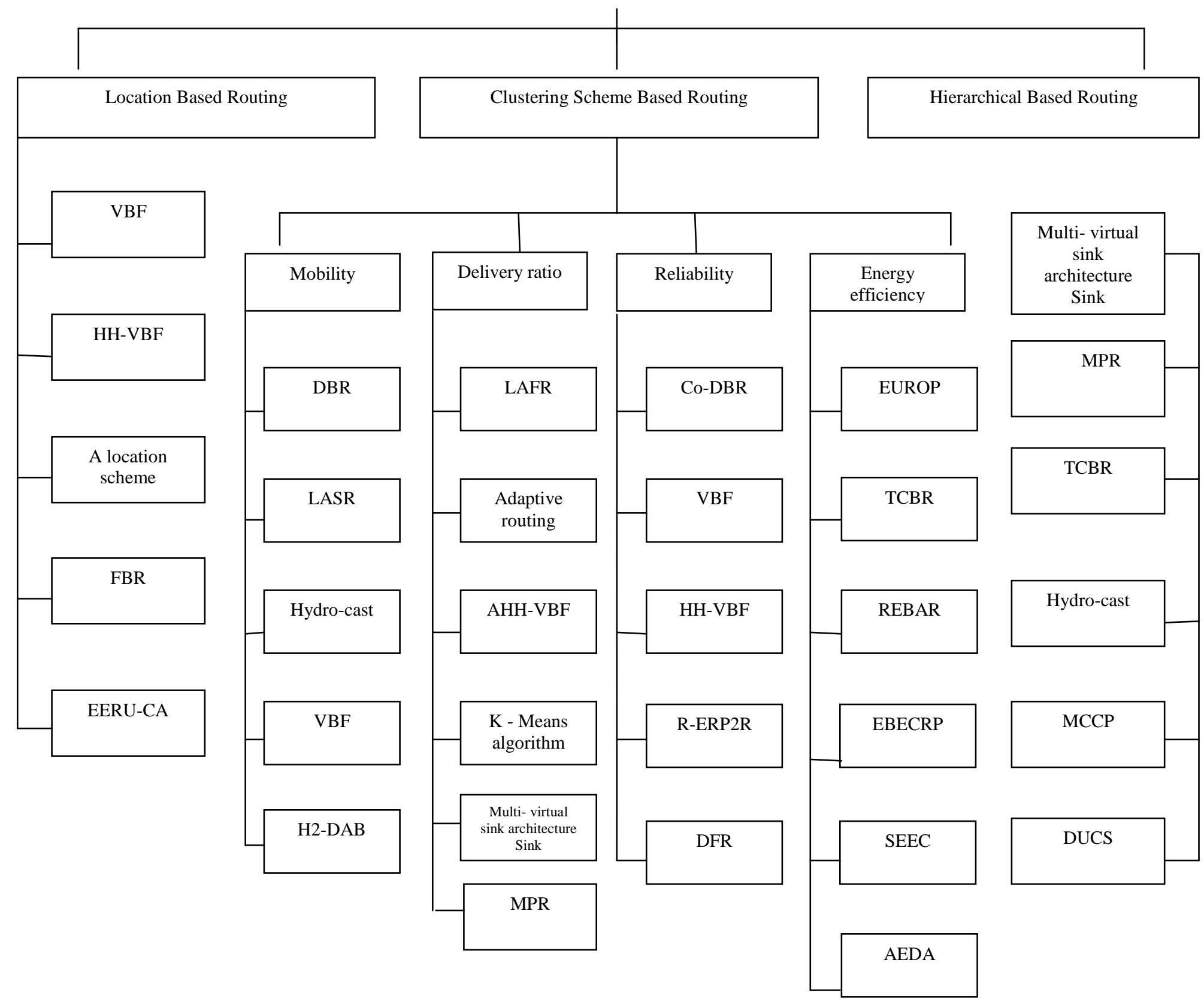

Figure 3: Taxonomy of UWSN protocols as signify by their capability [2] 
Table 1: Relationship of routing protocols in view of their qualities [2]

\begin{tabular}{|c|c|c|c|c|c|c|c|c|}
\hline $\begin{array}{l}\text { Protocol/ } \\
\text { Design }\end{array}$ & $\begin{array}{l}\text { Single/ } \\
\text { Numerous } \\
\text { duplicates }\end{array}$ & $\begin{array}{l}\text { Hop- } \\
\text { by-hop/ } \\
\text { end-to- } \\
\text { end }\end{array}$ & $\begin{array}{l}\text { Clustered } \\
\text { / single } \\
\text { substance }\end{array}$ & $\begin{array}{l}\text { Single/ } \\
\text { Numerous } \\
\text { base-station }\end{array}$ & $\begin{array}{l}\text { Hello or } \\
\text { control } \\
\text { packets }\end{array}$ & $\begin{array}{l}\text { Necessities } \\
\text { and } \\
\text { presumptions }\end{array}$ & $\begin{array}{l}\text { Learning } \\
\text { required/ } \\
\text { sustain }\end{array}$ & Comments \\
\hline VBF [8] & Numerous & $\begin{array}{l}\text { End-to- } \\
\text { end }\end{array}$ & $\begin{array}{l}\text { single } \\
\text { substance }\end{array}$ & $\begin{array}{l}\text { Single base- } \\
\text { station }\end{array}$ & No & $\begin{array}{l}\text { Geo. area is } \\
\text { accessible }\end{array}$ & whole system & $\begin{array}{l}\text { Considered as first } \\
\text { geographic routing } \\
\text { methodology for UWSN }\end{array}$ \\
\hline $\begin{array}{l}\text { HH-VBF } \\
\text { [9] }\end{array}$ & Numerous & $\begin{array}{l}\text { Hop-by- } \\
\text { hop }\end{array}$ & $\begin{array}{l}\text { single } \\
\text { substance }\end{array}$ & $\begin{array}{l}\text { Single base- } \\
\text { station }\end{array}$ & No & $\begin{array}{l}\text { Geo. area is } \\
\text { accessible }\end{array}$ & whole system & $\begin{array}{l}\text { Upgraded variant power } \\
\text { enhanced by presenting } \\
\text { Hop-by-hop approach rather } \\
\text { than end to end. }\end{array}$ \\
\hline $\begin{array}{l}\text { A } \\
\text { location } \\
\text { scheme } \\
{[10]} \\
\end{array}$ & Numerous & $\begin{array}{l}\text { End-to- } \\
\text { end }\end{array}$ & $\begin{array}{l}\text { single } \\
\text { substance }\end{array}$ & $\begin{array}{l}\text { Single base- } \\
\text { station }\end{array}$ & No & $\begin{array}{l}\text { Geo. area is } \\
\text { accessible }\end{array}$ & whole system & $\begin{array}{l}\text { It can achieve scalability } \\
\text { accuracy and it also made } \\
\text { the balance of the cost }\end{array}$ \\
\hline FBR [11] & $\begin{array}{l}\text { Single } \\
\text { duplicates }\end{array}$ & $\begin{array}{l}\text { Hop-by- } \\
\text { hop }\end{array}$ & $\begin{array}{l}\text { single } \\
\text { substance }\end{array}$ & $\begin{array}{l}\text { Numerous } \\
\text { base-station }\end{array}$ & Yes & $\begin{array}{l}\text { Geo. area is } \\
\text { accessible }\end{array}$ & $\begin{array}{l}\text { Personal and } \\
\text { sink area info. }\end{array}$ & $\begin{array}{l}\text { A cross-layer area based } \\
\text { approach, coupling the } \\
\text { routing, MAC, and physical } \\
\text { layers }\end{array}$ \\
\hline $\begin{array}{l}\text { EERU- } \\
\text { CA [12] }\end{array}$ & Numerous & $\begin{array}{l}\text { Hop-by } \\
\text { hop }\end{array}$ & Clustered & $\begin{array}{l}\text { Single-base- } \\
\text { station }\end{array}$ & No & $\begin{array}{l}\text { Geo. area is } \\
\text { accessible }\end{array}$ & whole system & $\begin{array}{l}\text { It is utilizing the concept of } \\
\text { a special node. A special } \\
\text { node is having abundant } \\
\text { energy and large } \\
\text { transmission power. }\end{array}$ \\
\hline DBR [13] & Numerous & $\begin{array}{l}\text { Hop-by- } \\
\text { hop }\end{array}$ & $\begin{array}{l}\text { single } \\
\text { substance }\end{array}$ & $\begin{array}{l}\text { Numerous } \\
\text { base-station }\end{array}$ & No & $\begin{array}{l}\text { Nodes with } \\
\text { Extraordinary } \\
\text { H/W }\end{array}$ & $\begin{array}{l}\text { No system } \\
\text { information } \\
\text { sustain }\end{array}$ & $\begin{array}{l}\text { Considered first depth } \\
\text { based routing. In come } \\
\text { around of getting } \\
\text { information packets, nodes } \\
\text { with lower depth will } \\
\text { acknowledge and remaining } \\
\text { disposes of. }\end{array}$ \\
\hline $\begin{array}{l}\text { LASR } \\
{[14]}\end{array}$ & $\begin{array}{l}\text { Single } \\
\text { duplicates }\end{array}$ & $\begin{array}{l}\text { End-to- } \\
\text { end }\end{array}$ & $\begin{array}{l}\text { single } \\
\text { substance }\end{array}$ & $\begin{array}{l}\text { Single-base- } \\
\text { station }\end{array}$ & Yes & $\begin{array}{l}\text { Network with } \\
\text { special setup }\end{array}$ & $\begin{array}{l}\text { Source to sink } \\
\text { information }\end{array}$ & $\begin{array}{l}\text { A DSR, adjustment area } \\
\text { and connection quality } \\
\text { mindfulness } \\
\text { incorporated. Favored just } \\
\text { for little systems. }\end{array}$ \\
\hline $\begin{array}{l}\text { Hydro- } \\
\text { cast [15] }\end{array}$ & Numerous & $\begin{array}{l}\text { Hop-by- } \\
\text { hop }\end{array}$ & Clustered & $\begin{array}{l}\text { Numerous } \\
\text { base-station }\end{array}$ & No & $\begin{array}{l}\text { Nodes with } \\
\text { Extraordinary } \\
\text { H/W }\end{array}$ & $\begin{array}{l}\text { 2-hop } \\
\text { neighbor's }\end{array}$ & $\begin{array}{l}\text { Comparative with DBR, } \\
\text { Anycast weight-based } \\
\text { routing, a subset of } \\
\text { forwarder nodes are chosen } \\
\text { to expand avaricious } \\
\text { advance. }\end{array}$ \\
\hline $\begin{array}{l}\text { H2-DAB } \\
{[16]}\end{array}$ & $\begin{array}{l}\text { Single } \\
\text { duplicates }\end{array}$ & $\begin{array}{l}\text { Hop-by- } \\
\text { hop }\end{array}$ & $\begin{array}{l}\text { Single- } \\
\text { substance }\end{array}$ & $\begin{array}{l}\text { Numerous } \\
\text { base-station }\end{array}$ & Yes & $\mathrm{n} / \mathrm{a}$ & $\begin{array}{l}\text { 1-hop } \\
\text { neighbor 's }\end{array}$ & $\begin{array}{l}\text { Short powerful addresses } \\
\text { called hop-IDs are utilized } \\
\text { for routing, allocated to } \\
\text { each node as indicated by } \\
\text { the depth positions. }\end{array}$ \\
\hline $\begin{array}{l}\text { LAFR } \\
{[17]}\end{array}$ & Numerous & $\begin{array}{l}\text { End-to- } \\
\text { end }\end{array}$ & $\begin{array}{l}\text { Multiple- } \\
\text { substance }\end{array}$ & $\begin{array}{l}\text { Single base- } \\
\text { station }\end{array}$ & Yes & $\begin{array}{l}\text { Network with } \\
\text { special setup }\end{array}$ & $\begin{array}{l}\text { 3-hop } \\
\text { neighbor's }\end{array}$ & $\begin{array}{l}\text { It makes smooth routing } \\
\text { criticism in UWSNs with } \\
\text { high extents of filter kilter } \\
\text { joins. }\end{array}$ \\
\hline $\begin{array}{l}\text { Adaptive } \\
\text { routing } \\
{[18]}\end{array}$ & Numerous & $\begin{array}{l}\text { Hop-by- } \\
\text { hop }\end{array}$ & $\begin{array}{l}\text { Single- } \\
\text { substance }\end{array}$ & $\begin{array}{l}\text { Single base- } \\
\text { station }\end{array}$ & Yes & $\mathrm{n} / \mathrm{a}$ & $\begin{array}{l}\text { Own and 1-hop } \\
\text { neighbors and } \\
\text { sink info }\end{array}$ & $\begin{array}{l}\text { Both, the packets and } \\
\text { system qualities are } \\
\text { considered before choosing } \\
\text { about the packet sent. }\end{array}$ \\
\hline $\begin{array}{l}\text { AHH- } \\
\text { VBF } \\
{[19]}\end{array}$ & Numerous & $\begin{array}{l}\text { Hop-by- } \\
\text { hop }\end{array}$ & $\begin{array}{l}\text { single } \\
\text { substance }\end{array}$ & $\begin{array}{l}\text { Single base- } \\
\text { station }\end{array}$ & No & $\begin{array}{l}\text { Geo. area is } \\
\text { accessible }\end{array}$ & whole system & $\begin{array}{l}\text { Adaptive hop-by-hop } \\
\text { vector-based sending is } \\
\text { greatly improved than that } \\
\text { of HH-VBF as far as } \\
\text { information delivery ratio, } \\
\text { energy utilization, and end- } \\
\text { to-end inertness. }\end{array}$ \\
\hline
\end{tabular}




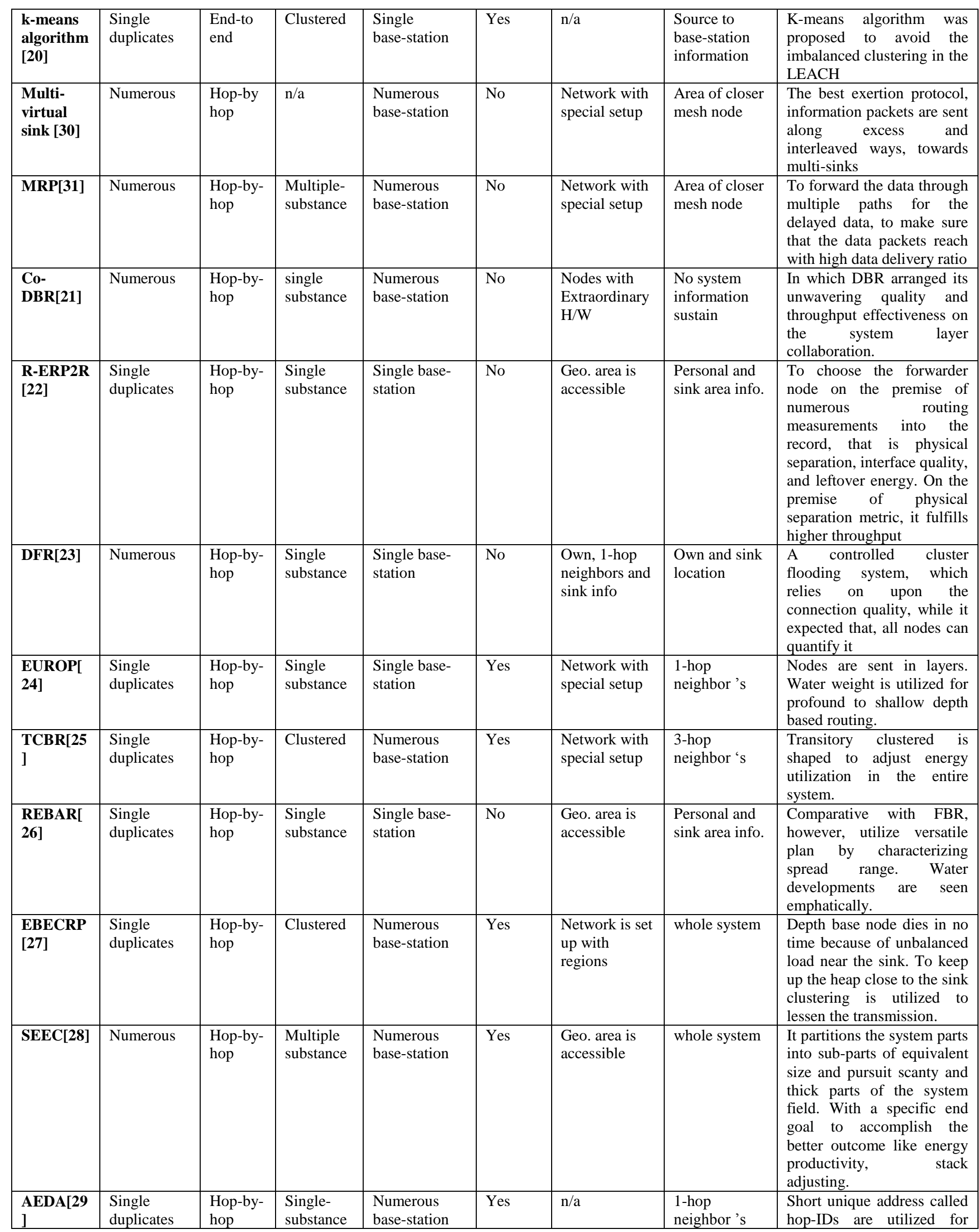




\begin{tabular}{|l|l|l|l|l|l|l|l|l|}
\hline & & & & & & & $\begin{array}{l}\text { routing, allocated to each } \\
\text { node as indicated by the } \\
\text { depth positions }\end{array}$ \\
\hline $\begin{array}{l}\text { MCCP[3 } \\
\text { 2] }\end{array}$ & $\begin{array}{l}\text { Single } \\
\text { duplicates } \\
\text { thop }\end{array}$ & $\begin{array}{l}\text { Hop-by } \\
\text { hop }\end{array}$ & Clustered & $\begin{array}{l}\text { Numerous } \\
\text { base-station }\end{array}$ & Yes & n/a & $\begin{array}{l}\text { 2-hop } \\
\text { neighbor 's }\end{array}$ & $\begin{array}{l}\text { 2-hop cluster development } \\
\text { calculation yet does not } \\
\text { encourage } \\
\text { correspondence. }\end{array}$ \\
\hline $\begin{array}{l}\text { DUCS[33 } \\
\text { m }\end{array}$ & $\begin{array}{l}\text { Single } \\
\text { duplicates }\end{array}$ & $\begin{array}{l}\text { Hop-by } \\
\text { hop }\end{array}$ & Clustered & $\begin{array}{l}\text { Single base- } \\
\text { station }\end{array}$ & Yes & n/a & $\begin{array}{l}\text { Source to } \\
\text { base-station } \\
\text { information }\end{array}$ & $\begin{array}{l}\text { Control packets of route } \\
\text { Foundation are done by the } \\
\text { information packets. }\end{array}$ \\
\hline
\end{tabular}

\section{RELATED WORK}

Location based routing:

In this sort of routing, sensor nodes are addressed by methods for their areas. The separation between neighboring nodes can be figured on the basis of similar to sign quality. Indeed, even regardless of the way that location data based directing conventions are viable, taking into worry that GPS gadgets are cheap in underwater. The execution of the location based routing protocols will be diminishing.

VBF proposed by "Peng-Xie, Jun-Hong Cui, Li Lao", [8] VBF: Vector-Based Sending protocols for UWSNs. VBF protocols are known as the novel based routing protocols. A novel based routing protocols intended for UWSN to address the routing issue in UWSNs. It is principally an area based routing approach. In this convention, no state data is required in the sensor nodes. Nodes near the routing vector can forward the message from source to goal. When a node accepts a packet, it first calculates its location and verifies if it is the routing pipe.

Enhancing the robustness of Area Based Directing for UWSNs, [9] proposed by "Nicolas Nicolaou, et.al." with a specific end goal to scramble the strength and overpowered these issues. It has been proposed an enhanced performance of VBF called hop by hop vector-based sending (HH-VBF) routing protocol. They utilize same directing channel as used in VBF from source to goal, but instead than utilizing the single routing channel. It will utilize hop by hop vector routing channel. Reenactment comes about uncover that HH-VBF creates better outcomes for packet delivery quantity, especially in insufficient region gap and VBF.

The localization proposed by "Kai Chen, Yi Zhou, Xinhua He", [10] for sensor nodes to choose their area. The troublesome issues in UWSNs are restricted transmission capacity, broken channel, and the cost. For huge scale, UWSN propose a hierarchical localization technique. The new techniques dwell of four sorts of nodes that are surface floats, DET (Separable Lift Handsets), stay nodes and customary nodes. Though surface floats furnished with worldwide situating framework (GPS), DET is connected to the surface floats and it can be increment and decline to communicate its position, Stay nodes can assess the node contact specifically with the surface floats, Standard nodes limitation through grapple nodes position data. Various leveled confinement technique can accomplish adaptability exactness and it additionally made adjust the cost.

FBR "Focused beam routing protocol for UWSNs" proposed by [11] "Jornet, Josep Miquel, and Stojanovic, Milica and Zorzi, Michele". It considers that all nodes recognize only its individual location and the final destination location. In the proposed protocol, variable broadcast power layer is used in the sending of the data packet, and this broadcast power has ordered from $\mathrm{P} 1$ to $\mathrm{P} n$. For all power layer, there is an identical communicate range in which is a cone of point rise up out of the source node to the goal, are wanted to forestall excess flooding of communicating inquiry. It is appropriate for systems containing both static and portable nodes, which are not basically comparing to a substantial scale controller. A source node must be responsive of its individual area and the last goal area, yet not those of different nodes.

EERU-CA proposed by [12], "Khan, Gulistan and Gola, Kamal Kumar and Ali, Wajid", energy efficient routing calculation for UWSN-A clustering Approach. UWSNs, characterize into two sections i.e. Area based protocols and area free routing protocols. In any case, Area-based protocols are not appropriate for UWSNs. Limitation in UWSNs is the most imperative issue. In this paper proposed energy efficient routing in UWSNs-A Grouping Approach (EERU-CA). EERU-CA is using the idea of an uncommon node. A unique node is having bottomless energy and vast transmission control. Be that as it may, vitality and separation are the fundamental parameters in which information exchanging ought to have the greatest energy and least separation at accepting unit.

\section{Clustering scheme based routing protocols:}

UWSNs that consider the energy efficiency, reliability, mobility, delivery ratios based on clustering routing protocols. In order to prolong the network lifetime clustering schemes give a major effort to decrease the energy consumption [39]. The outline of a productive and solid routing protocol in view of node versatility for the underwater condition is truly a testing issue. The research communities have tried to resolve the issues of node mobility through efficient proposed routing algorithms but still, research is required to design the more efficient mobility based routing algorithms [40].

Mobility based routing: In this area, the portability of underwater sensor nodes brought on by water streams is taken into a talk by the directing protocols. Because of the constant development of the sensor nodes, that is effectively broken, which will require additional vitality and prepare time to recover or restore the directing, so the protocols which take the node mobility into discourse likewise have great energy utilization and spread defer execution [40].

DBR proposed by "Hai Yan, Zhijie Shi, Jun-Hong Cui", [13] "DBR: Depth-based for UWSNs". Depth based protocol can use multiple sinks underwater. DBR needs just profundity data, rather than requiring the total confined data. The information parcels are communicated from higher to lower profundity sensor nodes. At the point when node sent the information bundle, right off the bat it will check its flow and current position with respect to the water surface. At that point, it will compute the present position and after that precede the information packages if its depth is littler than edge esteem generally disposes of that esteem. Simulation results show that 
DBR can acquire at least $95 \%$, high packet delivery ratio in the dense network.

LASR proposed by [14] "Carlson, Edward A and Beaujean, Pierre-Philippe and An Edgar", Area mindful routing convention for underwater acoustic systems. So as to handle the extensive idleness of acoustic channel LASR utilizes two procedures: 1) link quality metric, 2) location awareness. Whereas, dynamic source (DSR) rely upon only shortest path metric but in immensely mobile networks it leads to low efficiency in the network. Therefore giving better courses through the system, LASR reconstitutes this most limited way metric with expected transmission number (ETX). The second technique of LASR is location awareness in which it estimating the local network topology from the incoming transmission. The packet header unlimited to inclined, whereas hop count between the source and destination increase.

In order to overcome the limitations of geographic authors [15] proposed a hydraulic pressure based protocol called Hydrocast. This proposed protocol has two stages, the forward choice set, and the routine recuperation mode. In the first stage, it picks a cluster of neigh-exhausting nodes with the higher change towards the sink as the following bounce. At the point when the neigh-exhausting node gets the information after that, it will get to their need as per their separation to the goal. The various sensor nodes with lower needs will limit their transmissions after accepting the transmission (information or affirmation bundle) of a higher need node. By along these lines, the likelihood of crashes and access transmissions is limited. In the second stage, a routing recuperation mode is proposed to dispense with the void thoughts. On the off chance that there are no neighbors with lower weight levels a node is taken as a nearby greatest node. To determine this issue it permits avoid administration system. To forward the information parcels to this node, every nearby greatest node finds and stores the recuperation way to a node whose profundity is lower than itself.

UWSNs have a unique problem for providing an efficient communication [16]. "Ayaz M, Abdullah A" proposed distributed protocol for UWSN, in view of neighborhood data. This protocol doesn't require full dimensional area data. Rather than utilizing source or pre-jump, it utilizes the possibility of per-contact. Most imperative truth for H2-DAB is that delivery ratio is not in view of the thick or meager condition of the ranges. Reproduction result uncovers that it can accomplish high conveyance proportion in both inadequate and thick area.

Delivery ratio: It is characterized by the proportions of profitable parcels gets at the versatile sink to the amount of package sent to the portable sinks at normal time interim. [27]

A link-state based adaptive feedback protocol (LAFR) proposed by "Zhang, Song, and Li, Deshi and Chen, Jian" [17] for UWSNs. LAFR handles the effect of the pillar width and three-dimensional bearing for UWSNs. It makes smooth routing input in UWSNs with high extents of uneven connections. It utilizes a credit-based dynamic refresh component to diminish energy utilizations of frequently refresh directing tables. Re-enactment result uncovers that it can accomplish the better outcome as far as vitality utilization, measurements, the bundle conveyance proportion, normal end to end delay.

Amir Akhavan Kharazian "Adaptive Clusters in Wireless Sensor Network" In this paper [18] authors proposed that step by step instructions to build arrange lifetime with low energy nodes. The group head determination in view of the weighting of the neighboring nodes that the weights were computed in light of the energy leftover and the separation between nodes. The proposed calculations describe preferred execution over LEACH- C and it has result practically like Drain. LEACH-C is a concentrated calculation and the proposed calculation is appropriated calculation without need any worldwide data.

The protocol proposed by "Yu, Haitao, and Yao, Nianmin and Liu, Jun" [19] depends on HH-VBF, however by taking the power level, the separation to the goal node and the transmission extend into the record, the execution of versatile jump by-bounce vector-based sending (AHH-VBF) is greatly improved than that of $\mathrm{HH}-\mathrm{VBF}$ as far as information conveyance proportion, energy utilization, and end-to-end inertness.

"Zhang, Ying and Sun, Hongliang and Yu, Jiancheng" proposed [20] clustered protocol based on improved K-means algorithm for UWSNs. In LEACH arbitrarily chooses the group head and circularly make the nodes alternate to go about as cluster heads. The arbitrary choice of the group makes a beeline for the system energy awkwardness. In this paper, Kimplies calculation was proposed to keep away from the imbalanced grouping in the LEACH. The choosing of the essential group head depends on the cluster of the node and separation between the node and the cluster head. The outcomes delineate the think about amongst LEACH and LEACH-L, in which it can effectively build the system lifetime and adjust the energy utilization. Choose the set of the candidate of primary cluster middles according to the formula

Reliability: Reliability quality is a testing element for any kind of correspondence. For underwater situations, dependable conveyance of detected information to the surface sink is a testing errand when contrasted with sending the gathered information to the control focus.

CoDBR "cooperative depth based for UWSNs" proposed by [21] "Nasir, Hina, Javaid, Nadeem and Ashraf' for UWSNs. In which DBR arranged its unwavering quality and throughput effectiveness on the system layer participation. On the premise of profundity, data source node chooses two hand-off nodes. In which source nodes advances its information to transfer nodes and goal. By using the amplify-forward technique, relay node forwards the data to the destination.

R-ERP2R [22] proposed by "Wahid A, Lee S, Kim D", RERP2R stands for a reliable and energy efficient protocol based on physical distance and residual energy. To select the forwarder node on the basis of numerous measurements into the record, that is physical separation, interface quality, and remaining vitality. On the premise of physical separation metric, it achieves higher throughput. Be that as it may, in the information sending stage, it furnishes capable energy arrangement with better connection quality and expands the system lifetime.

"Hwang, Daeyoup, and Kim, Dongkyun", [23] DFR: a Directional flooding-based protocol for UWSNs. Mobility and packet loss degrades reliability. This Protocol improves unwavering quality by parcel flooding strategy. The supposition is that each node perceives about its individual area, the area of one bounce neighbors and that of the last goal. This protocol upgrades unwavering quality by packet flooding system.

\section{Energy efficient:}

In [24], authors proposed energy efficient protocol in UWSNs. The underwater acoustic channels are different from radio 
channels. In which underwater sensor nodes have limited resources like battery control, transmission capacity, recognition capacity, allotment potential and so on. An energyefficient protocol in UWSNs proposed, to decline the number of package transport in the system and decrease the power utilization.

"M. Ayaz, A. Abdullah, Low Tang Jung" [25] Temporary Cluster based for UWSN, TCBR protocols proposed for underwater monitoring mission. In enjoin to tackle the trouble of the node portability "temporary cluster-based protocols" has been proposed. However, according to their locations, it divides the sensor nodes into different clusters. That is not only for static and dynamic networks but also for hybrid networks also. In TCBR, where two types of nodes are used ordinary nodes and courier nodes in which ordinary nodes are used to sense the nodes and gather information and sent to the courier node. A few courier nodes are used, to deliver the data packet to base station from sender to receiver. These courier nodes will reach different depth levels and stop for a particular amount of time. Later than receiving the particular position, these will transmit hello packets so that ordinary nodes approximately they will be conscious of their existence. These hello packets can be familiar only contained by 4 hops and if an ordinary node obtains them from more than one courier node then it will transmit the data packet to a neighbouring contained by a particular amount of time, which is distinct in the Hello packet.

The authors consider the nonstop node movement because have an excellent effect on power stability [26]. Located on this ending, the reliable and energy balanced (REBAR) calculation is projected. In REBAR, the nodes contain different correspondence gathering as indicated by their separation to the base station node. The nodes near the base station node contain minor correspondence accumulation. The calculation can be equipped for declines the power usage of nodes near the base station node. Then again, node development can impact additional inconveniences than remuneration.

EBECRP [27] "Energy efficient and balanced energy consumption cluster based protocol" proposed by many authors to execute cluster located among base-station flexibility and avoid deepness base. In deepness base, short deepness nodes expire in denial time as the unstable weight on the nodes close to the base-station. In this manner, to deal with this issue, utilize portable sinks in EBECRP, to keep up the heap on the nodes. Clustering is used with a specific end goal to decrease the quantity of transmission to adjust the energy utilization and system lifetime. Nonetheless, result depicts that EBECRP accomplishes most astounding dependability period and system lifetime.

SEEC [28] "Sparsity-aware energy efficient clustering protocol for UWSNs" proposed by "Azam, Irfan, and Majid, Abdul and Ahmad". SEEC partition the system parts into sub-parts of equivalent size and hunt inadequate and thick parts of the system field with the assistance of (SSA) sparsity seek calculation and (DSA) density search calculation. With a specific end goal to accomplish the better outcome in like manner energy proficiency, stack adjusting and control the holes issue in scanty locales. Simulation comes about delineates that SEEC accomplishes better system lifetime, arrange strength and energy utilization than another protocol.

In UWSN [29] the nonstop node development the area data of the sensor nodes is hard to oversee. It is a most vital worry with water, keeping in mind the end goal to deal with the issue of the long propagation delay, temperamental connections.
Numerous calculations have been proposed so as to handle the issue of substantial spread deferral and untrustworthy connection quality. Be that as it may, the jump by-bounce dynamic tending to based (H2-DAB) directing convention creates to handle the issue of the node portability. Simulation result uncovers that $\mathrm{H} 2-\mathrm{DAB}$ can control effectively amid the quick changes where the development of the node is extremely occasional still need almost no overhead with a specific end goal to finish the undertakings.

Hierarchical: Hierarchical protocols based on network architecture. This study covers the basic architecture of the hierarchical protocols with data forwarding mechanism, route discovery, and maintenance. The issues with every hierarchical protocol are also mentioned in this study.

Keeping in mind the end goal to handle the issue of node sending in underwater the creator [30] proposed a multi-sink sharp protocol for UWSNs. For shallow-water coastal territory, it expects the 2D UWSN design. It contained the five noteworthy sorts of components like sensor node, work node, underwater sink, surface float and observing focus. A sensor node, work node, underwater sink shows up at the seabed through the wire while surface floats are at the sea surface and associated with the checking framework through the web. The correspondence should be possible in three stages; firstly each sensor node transmits its information to the nearest work node, besides, work node total the information and transmits the total to the underwater sink. At long last, the collected bundles are transmitted to the surface float through the web. Nonetheless, this convention demonstrates the outcomes in high bundle conveyance proportion, yet it has some issue like as the supposition work node not contains the data but rather it likewise about underwater sinks, node location and so on.

In [31] authors propose MPR (Multi-Path), This calculation accomplishment to lessen the end-to-end postpones in underwater systems by exchange the comparable package during the divergent route in a 2-steps neighborhood utilizing transfer nodes. This calculation gets lesser end-to-end postpone than VBF with a superior package delivery ratio.

Keeping in mind, the end goal to enhance the energy efficiency and builds the network lifetime minimum cost clustering protocol (MCCP) is a cursed clustering protocol proposed in [32]. The creators propose a Clustering driven cost-based improvement trouble for the cluster course of action. Despite the fact that cluster heads have the ability to forward the information in a multi-hop strategy to touch base at the sink, each node is nonexistent to have the capacity to land at the sink. The cluster head collection calculation does not ensure that the cluster heads far-far from the sink are competent to convey their information to other cluster heads.

DUCS distributed clustering scheme proposed by "Domingo, Mari Carmen, and Prior, Rui" [33]. DUCS is powerful selforchestrating protocol, wherever the course of action of the cluster is finished through the help of conveyed calculation. In DUCS sensor nodes are systematized into the cluster and the single node is chosen as a cluster head. The whole nodes forward information to their specific cluster head, whose expertise is to execute flag handling work to dispose of pointless information by communicating information to the base station in direct to spare the energy. DUCS technique is isolated enthused about two rounds: one is cluster course of action or cluster development strategy where the cluster head is chosen and second is framework method part, where information transmission exists. 


\section{PERFORMANCE COMPARISON OF UWSNS PROTOCOL}

Construct the protocol is a not easy task. All the nodes surrounded by UWSN should be accessible (Connectivity), even when the nodes within the network begin to be unsuccessful due to energy issues or other problems (Fault Tolerance). The protocol should also adjust network size and density (Scalability). We compare between all the surveyed protocols according to our studies and other related works [2] Components seeing that the amount of redistributing nodes in the network adjusts metrics production through the substance of data pack delivery, continuous interruption along with energy consumption. Thus, compare between these protocols with respect to sparse and dense networks. Table2, examination of protocols in light of their quality

Table 2 Execution attributes of the prefer protocols [2]

\begin{tabular}{|c|c|c|c|c|c|c|c|}
\hline Category & Protocol & $\begin{array}{l}\text { Delivery } \\
\text { proportion }\end{array}$ & $\begin{array}{l}\text { Energy } \\
\text { proficiency }\end{array}$ & $\begin{array}{l}\text { Delay } \\
\text { proficiency }\end{array}$ & $\begin{array}{l}\text { Bandwidth } \\
\text { proficiency }\end{array}$ & Reliability & Execution \\
\hline \multirow{3}{*}{$\begin{array}{l}\text { Location } \\
\text { based }\end{array}$} & VBF [8] & Low & Normal & Low & Normal & Low & Low \\
\hline & $\begin{array}{l}\text { A Location } \\
\text { scheme [10] }\end{array}$ & Low & Normal & Normal & Normal & High & Low \\
\hline & EERU-CA [12] & High & High & Normal & Normal & Normal & High \\
\hline \multirow[t]{9}{*}{ Cluster based } & DBR [13] & High & Low & High & Normal & High & High \\
\hline & LASR[14] & Normal & Normal & Low & Normal & Normal & Normal \\
\hline & Hydro-cast [15] & High & Normal & High & Normal & Normal & High \\
\hline & AHH-VBF [19] & High & High & High & High & Normal & High \\
\hline & $\begin{array}{l}\text { K-means } \\
\text { algorithm [20] }\end{array}$ & Normal & High & Low & Normal & Normal & High \\
\hline & Co-DBR [21] & Low & High & Low & Normal & High & High \\
\hline & R-ERPCR [22] & Normal & High & Low & Normal & High & Normal \\
\hline & DFR [23] & Normal & Low & Normal & Normal & High & Normal \\
\hline & EEROP [24] & Normal & Normal & Low & High & High & Normal \\
\hline \multirow[t]{4}{*}{ Hierarchical } & Multi-sink [30] & Normal & Low & Normal & Normal & High & Normal \\
\hline & MPR [31] & Normal & Low & Normal & Normal & High & Normal \\
\hline & MCCP [32] & Low & High & Low & Normal & Normal & Normal \\
\hline & DUCS [33] & Normal & Normal & Low & Normal & Low & Low \\
\hline
\end{tabular}

\section{CONCLUSION}

In this paper, we represent an outline of the clustering scheme and location based and hierarchical in UWSN. There are various parameters are taken into concern likewise energy efficiency, mobility, reliability and so on. The development of dynamic clustering techniques is regarded as, an essential research area, which helps us make the network more efficient and reliable. In this unique characteristics of UWSN have been discussed in which proposed protocols for these environments and highlighted the advantages and performance issues of each scheme. However, the taxonomy 
of UWSN protocols as signifies by their capability. There are many challenges in the underwater wireless sensor network that need to develop. The objective of this paper is to encourage researchers by providing the basis proposed scheme and to develop a foundation for the development of newly advanced schemes.

\section{REFERENCES}

[1] Ayaz, Muhammad, and Abdullah, Azween and Faye, Ibrahima and Batra, Yasir," An efficient dynamic addressing based protocol for underwater wireless sensor networks", Computer Communications Elsevier, Vol.35, No.4, 2012, pp.475-486.

[2] Ayaz, Muhammad, and Baig, Imran and Abdullah, Azween and Faye, Ibrahima, "A survey on techniques in underwater wireless sensor networks", Journal of Network and Computer Applications, Vol.34, No.6, 2011, pp.1908-1927

[3] Akyildiz, Ian F, and Pompili, Dario and Melodia, Tommaso, "Underwater acoustic sensor networks: research challenges", Ad hoc networks Elsevier, Vol.3, No.3, 2005, pp.257-279

[4] Mohsin Murad, Adil A. Sheikh, Muhammad Asif Manzoor, Emad Felemban and Saad Qaisar, "A Survey on Current Underwater Acoustic Sensor Network Applications", International Journal of Computer Theory and Engineering, IACSIT Press, Vol.7, No.1, 2015, pp.51.

[5] C. García Izquierdo, F. Bertiglia, "TRACEABILITY OF GROUND-BASED METEOROLOGICAL SURFACE TEMPERATURE MEASUREMENTS”,2012

[6] Akyildiz, Ian F, and Su, Weilian and Sankarasubramaniam, Yogesh and Cayirci, Erdal, "Wireless sensor networks: a survey", Computer Networks, Elsevier, Vol.38, No.4, 2002, pp.393-422

[7] Chong, Chee-Yee, and Kumar, Srikanth P, "Sensor networks: evolution, opportunities, and challenges", Proceedings of the IEEE, Vol.91, No.81, IEEE, 2003, pp.1247-1256

[8] Xie, P.; Cui, J.; Lao, L, "VBF: Vector-Based Forwarding Protocol for Underwater Sensor Networks", Proceedings of the 5th International IFIP-TC6 Networking Conference on Networking Technologies, Services, and Protocols; Performance of Computer and Communication Networks; Mobile and Wireless Communications Networks (Networking 2006), Springer, Coimbra, Portugal, 2006; pp. 1216-1221.

[9] Nicolaou N., See A., Xie P., Cui J., and Maggiorini D., "Improving the Robustness of Location-based for Underwater Sensor Networks", Proc. Of the OCEANS ${ }^{\text {ee } 07, ~ E u r o p e, ~ I E E E, ~} 2007$.

[10] Kai Chen, Yi Zhou, Jianhua He, "A localization scheme for Underwater Wireless Sensor Networks", International Journal of Advanced Science and Technology, Vol.4, 2009

[11] Jornet, Josep Miquel, and Stojanovic, Milica and Zorzi, Michele, "Focused beam protocol for underwater acoustic networks", Proceedings of the third ACM international workshop on Underwater Networks, ACM, 2008, pp. 75-82.

[12] Khan, Gulistan and Gola, Kamal Kumar and Ali, Wajid,
Energy Efficient Algorithm for UWSN - A Clustering Approach Advances in Computing and Communication Engineering (ICACCE),2015 Second International Conference on 2015, IEEE

[13] Hai Yan, Zhijie Shi, Jun-Hong Cui, "DBR: Depth-based for Underwater Sensor Networks", in Proceedings of Networking'08, Singapore, May 5-9, 2008.

[14] Carlson, Edward A and Beaujean, Pierre-Philippe and an Edgar, "Location-aware protocol for underwater acoustic networks", OCEANS 2006, IEEE, pp.1-6.

[15] Lee, U., Wang, P., Noh, Y., Vieira, F. L., Gerla, M., \& Cui, J. H, "Pressure for Underwater Sensor Networks", INFOCOM, 2010 Proceedings IEEE, San Diego, CA, USA: IEEE, pp. 1-9

[16] Ayaz M, Abdullah A "Hop-by-hop dynamic addressing based (H2-DAB) protocol for underwater wireless sensor networks", In Information and Multimedia Technology, 2009. ICIMT’ 09. International Conference on 2009 Dec 16. IEEE

[17] Zhang, Song and Li, Deshi and Chen, Jian, "A link-state based adaptive feedback for underwater acoustic sensor networks", IEEE sensors journal, IEEE 2013, Vol.13, No.11,pp.4402-4412

[18] Amir Akhavan Kharazian, Kamal Jamshidi and Mohammad Reza Khayyambashi "ADAPTIVE CLUSTERING IN WIRELESS SENSOR NETWORK: CONSIDERING NODES WITH LOWESTENERGY", International Journal of Ad hoc, Sensor \& Ubiquitous Computing (IJASUC) Vol.3, No.2, April 2012

[19] Yu, Haitao, and Yao, Nianmin and Liu, Jun, An adaptive protocol in underwater sparse acoustic sensor networks, Ad Hoc Networks, Elsevier, 2015, vol.34, pp.121-143.

[20] Zhang, Ying and Sun, Hongliang and Yu, Jiancheng, "Clustered Protocol Based on Improved K-means Algorithm for Underwater Wireless Sensor Networks", Cyber Technology in Automation, Control, and Intelligent Networks (CYBER), 2015 IEEE International Conference on,year-2015, IEEE

[21] Nasir, Hina and Javaid, Nadeem and Ashraf, Hafsa and Manzoor, S and Khan, Zahoor Ali and Qasim, Umar and Sher, M, "CoDBR: cooperative depth based for underwater wireless sensor networks", Broadband and Wireless Computing, Communication and Applications (BWCCA), 2014 Ninth International Conference on, IEEE, 2014, pp. 52-57.

[22] Wahid, Abdul, and Lee, Sungwon and Kim, Dongkyun, "A reliable and energy-efficient protocol for underwater wireless sensor networks", International Journal of Communication Networks, IEEE, 2014 Vol.27, No.10, pp.2048-2062.

[23] Hwang, Daeyoup, and Kim, Dongkyun, DFR: Directional flooding-based protocol for Underwater Sensor Networks pages- $\{1-7\}$, Year-2008, IEEE

[24] Chun-Hao Yang; Kuo-Feng Ssu, "An energy-efficient protocol in Underwater Sensor Networks", in Sensing Technology, 2008. ICST 2008.

[25] M. Ayaz, A. Abdullah, Low Tang Jung, "Temporary cluster based for Underwater Wireless Sensor 
Networks", in Information Technology (ITSim), 2010 International Symposium on, vol. 2, June 2010

[26] Chen, Jinping and $\mathrm{Wu}$, Xiaobing and Chen, Guihai, "REBAR: A reliable and energy balanced algorithm for UWSNs", Grid and Cooperative Computing, 2008. GCC'08. Seventh International Conference on IEEE, pp.349-355

[27] Majid, Abdul and Azam, Irfan and Waheed, Abdul and Zain-ul-Abidin, Muhammad and Hafeez, Taimur and Khan, Zahoor Ali and Qasim, Umar and Javaid, Nadeem, "An energy efficient and balanced energy consumption cluster based protocol for underwater wireless sensor networks", Advanced Information Networking and Applications (AINA), 30th International Conference on 2016, IEEE, pp.324-333.

[28] Azam, Irfan and Majid, Abdul and Ahmad, Ijaz and Shakeel, Usman and Maqsood, Hamad and Khan, Zahoor Ali and Qasim, Umar and Javaid, Nadeem, "SEEC: Sparsity-aware energy efficient clustering protocol for underwater wireless sensor networks". Advanced Information Networking and Applications (AINA), 2016 IEEE 30th International Conference on 2016, IEEE, pp.352-361.

[29] Ayaz, Muhammad, and Abdullah, Azween, and Faye, Ibrahima and Batista, Yasir, "An efficient Dynamic Addressing based protocol for underwater wireless sensor networks". Computer Communications, Vol.35, 2012

[30] Li, Tonghong, Multi-sink opportunistic protocol for underwater mesh network, Communication, circuits networks, ICCCAS 2008 International Conference on, IEEE, pp.404-409

[31] Chen, Y.S.; Juang, T.Y.; Lin, Y.W.; Tsai, I.C. "A low propagation delay multipath protocol for underwater sensor networks". J. Internet Technology 2010, Vol.11, pp.153-166.

[32] Wang, P.; Li, C.; Zheng, J. "Distributed Minimum-Cost Clustering Protocol for UnderWater Sensor Networks (UWSNs)". Proceedings of the IEEE International Conference on Communications (ICC '07), Glasgow, UK, 24-28 June 2007; pp. 3510-3515

[33] Domingo, Mari Carmen and Prior, Rui, "A distributed clustering scheme for underwater wireless sensor networks", Personal, Indoor and Mobile Radio Communications, 2007. PIMRC 2007, IEEE 18th International Symposium on 2007, IEEE, pp.1-5

[34] Gkikopouli, Andrianna, George Nikolakopoulos, and Stamatis Manses. "A survey on underwater wireless sensor networks and applications." Control \& Automation (MED), 2012 20th Mediterranean Conference on. IEEE, 2012.

[35] Po-Jen Chuang, Sheng-Hsiung Yang, and Chi-Shin Lin," Energy-Efficient Clustering in Wireless Sensor Networks", Springer-Verlag Berlin Heidelberg, 2009

[36] S. JERUSHA, K.KULOTHUNGAN \& A. KANNAN, "LOCATION AWARE CLUSTER BASED IN WIRELESS SENSOR NETWORKS”, 2012 International Journal of Computer \& Communication Technology ISSN

[37] Ahmed M., "Iraqi Rivers Pollution Monitoring Network Based on Underwater Wireless Sensor Networks", a thesis submitted to the Computer Engineering Department University of Technology in Partial Fulfillment of the requirements for the Degree of Master of Science in computer engineering, 2013.

[38] Salvador Climent, Juan Vicente Capella, Nirvana Meratnia and Juan José Serrano, "Underwater Sensor Networks: A New Energy Efficient and Robust Architecture Sensors", 2012, 12, pp.704-731.

[39] Ovaliadis, K, and Savage, N, Cluster protocols in underwater sensor networks: a research review, Journal of Engineering Science and Technologyreview.2014.vol.7.no.3.pp.171-175.

[40] Ahmed, Mukhtar, and Salleh, Mazleena and Channa, M Ibrahim, protocols based on node mobility for Underwater Wireless Sensor Network (UWSN): A survey, Journal of Network and Computer Applications, Elsevier, 2017, vol.78, pp.242-252.

[41] Xie, Peng and Zhou, Zhong and Nicolaou, Nicolas and See, Andrew and Cui, Jun-Hong and Shi, Zhi, Efficient vector-based forwarding for underwater sensor networks.

[42] EURASIP Journal on Wireless Communications and Networking, Springer, Vol. 2010, pp. 195910, 2010. 